\title{
Features of Unbalanced Effect of Talent Agglomeration in Sports Industry Clusters
}

\author{
Lei Lei \\ Sports department, Northwest A\&F University dept of Physical Education,Xianyang, \\ Shaanxi, China
}

\begin{abstract}
In the process of development of sports industry cluster, the agglomeration level of human resources, which is an important factor, will be uneven, resulting in shortage or excess of talent resources, which will lead to the loss of output benefits of the sports industry. Besides, the difference between the individual's judgment which is based on the subjective value of the balanced level and the actual level of talent agglomeration will also affect the effect of the talent agglomeration of sports industry cluster and hinder the long-term development of the sports industry cluster. This study analyzes the features of unbalanced effects of talent agglomeration in sports industry cluster from the perspective of economics, sociology, and psychology, and provides reference for the development of sports industry cluster.
\end{abstract}

KEYWORDS : Sports Industry Cluster ; Talent Agglomeration ; Unbalanced Effects

\section{Introduction}

In October 2014, the State Council of the People's Republic of China issued the guidance document named Several Opinions on Accelerating the Development of the Sports Industry and Promoting Sports Consumption ${ }^{[1]}$. Along with the continuous improvement of social and economic development levels ${ }^{[1]}$, China has bid for a series of international events such as the Winter Olympics, Asian Games and the Universiade. China's sports industry has made great progress, and the importance of the development of the sports industry has also been raised to an unprecedented height ${ }^{[2]}$. Local governments and investors have also shown strong interest in the development of the sports industry. Sports industry bases, sports industrial parks, and sports industry function zones have been established one after another. Various types of sports industries have exhibited the cluster development and have strong competitive advantages.

The concept of industrial cluster was proposed by Professor Michael Boer of Harvard University in 1990 and first appeared in the book National Competitive Advantage. Industrial cluster is a new form of industrial organization with the 
advantages of more efficient internal resource allocation and greater competitive advantages, which has a stronger promoting effect on the economic development of local regions ${ }^{[3]}$. Professor Michael Boer has explained: "For the cluster industry, geographic concentration is like a magnetic field, attracting senior talents and other key elements.” The process of industrial agglomeration is usually accompanied by a large number of human resources agglomeration, and through this process, the talents can also help industrial clusters improve rapidly and promote the formation and development of industrial cluster. Most importantly, the agglomeration effect caused by the talent agglomeration has important significance for improving the industry's ability to maintain innovation ${ }^{[4]}$.

In the process of sports industry agglomeration, if talent resources, an important resource for the sports industry, integrate into the agglomeration area by the speed and scale of agglomeration which don't match the development of the sports industry will have a negative impact. Judging from the existing results of research on the accumulation of talents in the sports industry cluster, most researches focused on human resources as one of the influencing factors in the development of sports industry clusters, and has not studied the equilibrium phenomenon of talent agglomeration in sports industry cluster. In general, the speed and scale of sports talents agglomeration should be reasonably matched with the development of sports industry cluster. Too fast or too slow talent agglomeration, or too large or too small talent agglomeration scale is not conducive to the development of sports industry clusters. Domestic scholar Song $\mathrm{Yu}^{[5][6][7]}$ concluded that the clustered development of China's sports industry is unbalanced through the empirical analysis of China's sports industry agglomeration and cluster evolution. This imbalance is mainly reflected in the development of urban and rural sports industry and the development of regional sports industry. Therefore, this paper studies the unbalanced effects of talent agglomeration in sports industry cluster, enriching the research results of the talent agglomeration theory in sports industry cluster and providing theoretical guidance and practical reference for the management of human resources in the development of sports industrial cluster.

\section{Features of Talent Agglomeration in Sports Industry Cluster}

Sports industry agglomeration zone is a functional zone based on the integrated development of sports and relative industries, with a distinct feature of space agglomeration, and the industry zone as well as the openness of public space promote mutually. The development of sports industry cluster can provide great environment to attract, cultivate and motivate sports talents, attracting large amount of talents through the sports industry agglomeration zone. While the talent resources agglomeration gives the sports industry cluster strong personnel support to make deeper and further development. Chinese scholars have gained many research achievements about the sports industry cluster, while only a few studies focus on the talent agglomeration phenomenon in sports industry cluster. In conclusion, the existing study on the interaction between the development of sports industry cluster and the agglomeration of talent resources mainly targets at three aspects: (1) 
Analysis of the requirement type of the talent resources during the development of sports industry cluster. Different types of sports industries need different types of professional talents, and different scales of sports industries ask for talents in different levels ${ }^{[4][7][12]}$. (2) Measure of the talent agglomeration scales in the sports industry cluster, including the scales of the employees in the sports industry, the research and development personnel in the sports industry, and the sales and service staff, to analyze the influence of the talent agglomeration scale to the sports industry cluster $^{[13][14][15]}$. (3) Analysis of the influencing factor of the formation of sports industry cluster made by the human resource cost. The sports industry mainly includes many types such as physical sports products and virtual sports services. Different types of sports industries have different needs for human resource cost ${ }^{[14]}$ [16][17]. The research results show that in the process of the development of sports industry cluster, the development of sports industry cluster and sports talents cluster are closely related and influence each other. Only the development between them is balanced can they play a role in promoting each other.

\section{Unbalanced Phenomenon of Production Factors in Sports Industry}

Production factor refers to the economic resources that people need to invest in order to produce a product or provide a service in the process of economic production. In the development process of sports industry, the quantity and quality of production factor, the proportion of various production factors, whether the allocation of various resources in production factor is reasonable, and the efficiency of allocation of various production factor determine the process and results of the development of the whole sports industry [ 9 ]. In general, the sports industry can achieve the lowest input of production resources and the highest benefits through the rational allocation of various production factors. This state is the best state for the development of the sports industry. Factors of production need to maintain a balanced state, that is, when one or more production factors increase to a certain extent, other production factors also need to change in order to achieve a matching optimal state. If the number of some production factors remains the same while the other one or more production factors increase or decrease to a certain extent, there will be too many or too few input factors, which will harm the development of production and greatly reduce the output efficiency. At this time, the production factors are in unbalance. US scholar D McFadden [ 7 ] first applied the concept of describing the balance state of production factors to the study of economics. The unbalanced state of production factors mainly refers to the decrease in the utilization capacity of production factors caused by the imbalanced collocation of various kinds of production factors. The popular expression is that for the factors of production in the sports industry, it is necessary to ensure that all kinds of production factors are in a relatively balanced state so as to avoid the problems of excessive or insufficient resources in the sports industry caused by too much or too little investment. 


\section{Unbalanced Effect of Sports Talent Agglomeration}

Based on the existing research on industrial cluster and talent agglomeration, it can be seen that only when the degree of talent agglomeration matches the scale of the local sports industry cluster can ensure the healthy development of the sports industry. Neither too many nor too few talent agglomeration is the ideal state for the development of the local sports industry. Similarly, in the development of sports industry cluster, a large number of employment opportunities will be created in the region, and a good environment for the development of sports talents can be provided. Various advantageous conditions can attract more and more talents to gather in sports industry clusters to produce agglomeration effects. The agglomeration effects of these talents will accelerate the development of sports industry clusters. However, in the practical process of the development of sports industry clusters, it is not very realistic to require the development of sports industry clusters to completely match the demand for talents.

Based on the deficiency of the existing research on the talent agglomeration effect of sports industry clusters, this paper mainly discusses the imbalance of talent agglomeration effect. First of all, the unbalanced effects of sports talent agglomeration refers to that in the process of sports industry agglomeration, the scale and speed of talents entering the industrial agglomeration area do not match the demand of sports industry development for talents, resulting in shortage or surplus of talent resources, and the benefits of sports talent resources have not been maximized. Secondly, the unbalanced state of talent accumulation falls within the scope of psychological research. This hypothesis is related to cognitive structure, process and changes. In the 1940s, American social psychologist $f$ De analyzed ${ }^{[7]}$ : The cognitive process can be divided into cognitive elements. There is a mutual relationship between the cognitive elements. The relationship is either positive or negative. Each cognitive element constitutes a cognitive system. The cognitive system is analyzed to find out the conditions and laws of balance or unbalance in the cognitive system. When the cognitive system is in an unbalanced state, it will cause the main body to produce unpleasant emotions and other emotions, causing psychological pressure on the main body and driving the cognitive main body to make decisions based on the balanced basis. Therefore, from the perspective of sports economics, the unbalanced agglomeration of talents is due to an objective existence state that the input of production factors does not match the development needs of sports industry clusters. From the perspective of psychology, it is because one can judge the match between the number of talents already possessed by sports industry clusters and the number of talents that can be accommodated according to one's own cognition. Obviously, there are two kinds of balance for the talent agglomeration of sports industry cluster, one is the objective balance of talent resources and the other is the balance of psychological cognition. Therefore, the imbalance of talent agglomeration of sports industry clusters will occur in the following situations: (1) When the scale of development of sports industry cluster has reached an ideal scale, the continuous influx or departure of human resources will lead to an unbalanced state. (2) When the sports industry cluster has not reached the ideal scale, the demand for talents is less than the number of talents cluster, the 
actual number of talents in the sports industry cluster area is far more than the amount of talents needed for the development of the sports industry cluster, and the number of talents cluster is " surplus" resulting in the unbalanced state of talents cluster. (3) When the sports industry cluster has not reached the ideal scale, the number of talents cluster cannot meet the demand of talents. The actual number of talents in the sports industry cluster area is less than the number of talents needed for the development of the sports industry cluster. The "insufficient" number of talents cluster will also lead to the unbalanced state of talents cluster. (4) When the sports industry cluster has not reached the ideal development state, the number of talents gathered in the sports industry cluster is larger than / less than the amount of talents needed for the development of the current sports industry. Due to the difference in personal subjective cognition, it is impossible to objectively judge the internal talents agglomeration situation of the cluster which the person belongs to, and it is considered that the degree of the talent agglomeration which he belongs to is in a "balanced" state. Therefore, in different stages of the development of sports industry agglomeration, it is possible to appear an imbalance of sports talents agglomeration in each stage. The (1) (2) and (3) phenomena describe an unbalanced state of sports talents resources as production factors from the perspective of economics. The (4) phenomena are subjective feelings under the state of psychological cognition and the state of differential feelings of interaction between cognitive subject and cognitive object.

\section{Conclusion}

The formation of sports industry clusters has effectively promoted the development of China's regional sports industry and the importance of sports industry to regional economic competitiveness. At the same time, the sustainable development of sports industry cluster cannot be separated from the strong support of human resources. The sports industry clusters in China are mostly in the growth stage. How to take reasonable measures to improve the attraction of sports industry clusters to talent agglomeration and accelerate talents agglomeration to sports industry cluster regions? At the same time, it is necessary to consider the balanced relationship between talent agglomeration and actual demand to prevent the shortage or surplus of talent agglomeration, avoid the loss or waste of good talent resources in the sports industry and promote the optimization of the benefits of talent resources in the sports industry.

\section{References}

[1] Huo Pengxiang, Deng Luoping, Wang Haiming (2018). Study on the measurement of competitiveness level and influencing factors of sports industrial clusters in central China. Journal of Shenyang Physical Education Institute, (01): $1-5$

[2] Wang Guifang (2017). Research on the status quo and countermeasures of spatial agglomeration development of sports industry: Taking Shandong 
Province as an example . Journal of Shandong Institute of Physical Education, 33(02):27-31.

[3] Sun Suling (2016). Evaluation Index system and empirical study on the potential of Regional Sports Industry[D]. Shanghai Institute of Physical Education.

[4] Wang Yan, Wang Yue, Wu Yuming, Yin Guangwei (2016). Research on the Relation between Spatial Agglomeration and Sports Industry Growth-—Based on Empirical Analysis of SLM and SEM Models . Economic Survey, 33(05): 7883.

[5] Guo Hengtao, Li Yanxi (2015). The evolution and development of the spillover effect of sporting goods industry agglomeration . Journal of Wuhan Institute of Physical Education , 49(10):46-49+95.

[6] He Jieming (2015). Sports industry and mass sports linkage logic and threedimensional path . China Sports Science and Technology, 51(04):111-116.

[7] Han Wenchao, He Song, Li Yazhou (2015). Spatial development model of sports industry clusters at home and abroad and its inspiration . Planner, 31(07):30-35.

[8] Song Yu (2015). Research on Progress and Cluster Evolvement of China's Sports Industry (1994-2012) . Journal of Xi'an Institute of Physical Education, 32(01): 1-10+21.

[9] Zheng Meiyan, Wang Xuefeng (2017). Research on Core Competence Evaluation System of Sports Industry Cluster in China- - Based on the Perspective of Improving Traditional Model . Journal of Shandong Institute of Physical Education, 33(02):27-31.

[10] Xu Haojian (2014). Development path and Promotion Strategy of Sports industry agglomeration . Journal of Nanjing Institute of Physical Education(Natural Science) ,13(03):153-155.

[11] Wei Huoyan (2014). An Empirical Study on the Development of Regional Sports Industry Clusters: A Case Study of the Central Plains Economic Zone . Journal of Yunnan University of Finance and Economics, 30(02):74-82.

[12] Xing Zunming, Cheng Yihui, Yan Wei, Meng Qingguang, Chen Hongyu (2014). National Sports Industry Base: Implementation process, characteristics analysis and promotion strategy . Sports Science, 34(01): 66-74.

[13] Zhu Jianyong, Zhan Yilei, Zhu Wengang (2018). Research progress and trend of China's sports industry cluster . Sports Culture Guide, 2013(09):90-92.

[14] Song Yu (2013). Research on cluster development of sports industry: China's experience and problems . Journal of Beijing Sport University, 36(08): 17-23.

[15] Hu Yi, Zhu Puyi (2013). Research on Industrial Cluster Talent Agglomeration . Scientific and Technological Progress and Countermeasures,, 30(19): 130-134.

[16] Xu Maowei, Guan Wenchao (2012). Dynamic mechanism of China's sports industry agglomeration . Journal of Shanghai University of Sport, 36(03):57-60.

[17] Gong Wen (2011). Level measurement and influencing factors of China's sports industry agglomeration[D]. Hunan University.

[18] Song Yu (2011). Research on the Agglomeration and Clustering Development of China's Sports Industry (1994-2010) [D]. Nanjing Normal University.

[19] Zhou Junxu, Hu Yi (2010). Industrial Clusters' Talent Gravity Effect and Cause Analysis: Taking Foshan as an Example . Management Review, 22(03): 101-107.

\section{Published by Francis Academic Press, UK}


[20] Chen Liuqin (2009). Rational and orderly development of industrial clusters requires local governments to make a difference . Journal of Jilin Institute of Business and Technology, 25(01):14-19.

[21] Sui Guangjun, Shen Minghao (2004). Dynamic analysis of the life cycle evolution of industrial agglomeration . Economics Dynamic, (11):39-41.

[22]Slaper, T.F., Harmon, K.M., Rubin, B.M (2018). Industry Clusters and Regional Economic Performance:A Study Across U.S. Metropolitan Statistical Areas, Economic Development Quarterly, 32 (1), pp.44-59.

[23]Suchacek, J., Stverkova, H., Kasik, J (2018). Czech machinery cluster and its role in sustainable development of Moravian-Silesian enterprises during the posttransformation era , Sustainability (Switzerland), 10 (2), NO.239, .

[24]Casali, G.L., Perano, M., Tartaglione, A.M., Zolin, R (2018). How business idea fit affects sustainability and creates opportunities for value co-creation in nascent firms (2018) Sustainability (Switzerland), 10 (1), NO.189, .

[25]Yalyalieva, T.V., Napolskikh, D.L (2017). Modeling the processes of regional development based on geostatistics methodology, Regional Science Inquiry, 9 (2), pp.223-229.

[26]Pezoa-Fuentes, C., Vidal-Suñé, A (2017). Cluster perpetuation:Maintenance of competitive advantages over time.The case of Chile's large north, Resources Policy, 54, pp.176-188. 